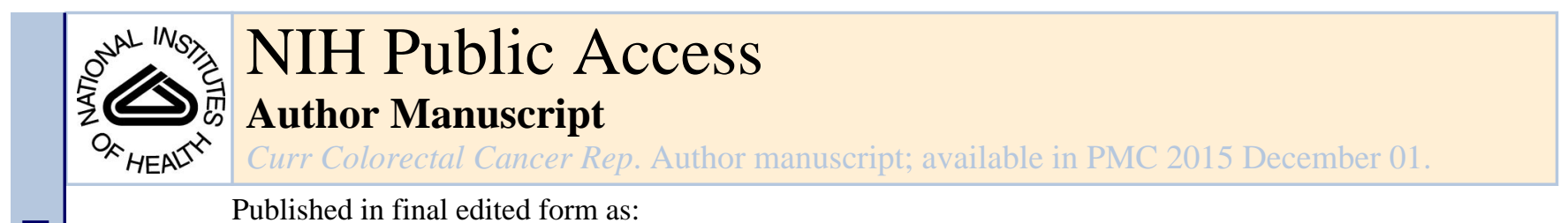

Published in final edited form as:

Curr Colorectal Cancer Rep. 2014 December 1; 10(4): 417-424. doi:10.1007/s11888-014-0253-2.

\title{
Histone Demethylases in Colon Cancer
}

Santanu Paul ${ }^{1}$, Satish Ramalingam ${ }^{2}$, Dharmalingam Subramaniam², Joaquina Baranda ${ }^{3}$, Shrikant Anant ${ }^{1,2}$, and Animesh Dhar ${ }^{1,2}$

${ }^{1}$ Cancer Biology, University of Kansas Medical Center, Kansas City, Kansas

${ }^{2}$ Molecular and Integrative Physiology, University of Kansas Medical Center, Kansas City, Kansas

${ }^{3}$ Hematology \& Oncology, University of Kansas Medical Center, Kansas City, Kansas

\begin{abstract}
Cell growth and proliferation are controlled through different posttranslational modifications including demethylation, a process regulated by regulated by the demethylase enzymes. This review focuses on our current understanding of functional and therapeutic potentials of histone demethylases in colon cancer. Colon cancer is the third most common malignancy worldwide and the second leading cause of cancer deaths in the United States. The key protein families responsible for demethylation of histones, histone demethylases, have emerged as new therapeutic targets in different cancer types including colon cancer. These families are of great interest as potential novel biomarkers for diagnosis and targets for therapy and prevention of colon cancer. In this manuscript, we will discuss our current understanding of the histone demethylase family, and the role they play as epigenetic activators or repressors of different genes in colon cancer.
\end{abstract}

\section{Keywords}

Colon Cancer; Histone Lysine Demethylases; KDM; JMJD; LSD; Epigenetic

\section{Introduction}

Chromatin is a complex of proteins (histones or non-histone0 with DNA wrapped around it in the eukaryotic cells. Modifications of histones and DNA by methylation alter the physiological phenomena of cells (1). These modifications are mentioned as epigenetic alterations and this facilitates the transcriptional activity of gene expression due to different signals inside or outside of cells and in turn strengthens chromatin architecture. Some

\footnotetext{
*Corresponding Author: Animesh Dhar, PhD, Cancer Biology, The University of Kansas Medical Center, 3901 Rainbow Blvd., Kansas City, KS 66160, adhar@kumc.edu.

Compliance with Ethics Guidelines

Human and Animal Rights and Informed Consent

This article does not contain any studies with human or animal subjects performed by any of the authors.

Conflict of Interest

Santanu Paul declares that he has no conflict of interest.

Satish Ramalingam declares that he has no conflict of interest.

Dharmalingam Subramaniam declares that he has no conflict of interest.

Shrikant Anant declares that he has no conflict of interest.

Animesh Dhar declares that he has no conflict of interest.
} 
alterations of histones either by acetylation or by phosphorylation are highly vibrant, whereas others such as histone methylation could be more robust. Histone lysine methylation is stable and its amino-methyl group is difficult to split from the N-CH3 bond. The enzymatic reaction demonstrated that it would remove a histone lysine methyl mark to generate epigenetic mark. There are significant discoveries in the field of epigenetic including the innovation of histone lysine demethylase (5).

\section{Histone Lysine Demethylases}

Genetic information is stored in chromatin and this preserves the pattern of gene expression (6). Histone lysine methylation has been shown to be a stable chromatin modifier that together with DNA methylation describes epigenetic alterations (6). After the discovery of histone lysine demethylases, its epigenetic potential for histone lysine demethylation has been demonstrated to remove methyl marks in reversible manner (6). This activity of histone lysine methyl marks do not change the epigenetic alterations. All histone lysine methylation residues are reversible and play important roles in establishing cellular entity. The methylated histone lysine residues have been labeled as epigenetic marks due to its stable entity $(2,6)$. The enzyme cannot cleave the $\mathrm{N}-\mathrm{CH} 3$ bond directly but induces amine oxidation of methylated histone $\mathrm{H} 3$ lysine 4 (H3-K4) to generate unmodified lysine and formaldehyde (Figure 1A and B). This is a plausible mechanism with solid in vitro evidence using recombinant enzyme and various histone peptides, where conversion of the substrates is detected by mass spectrometry. Oxidation of amino-methyl requires the cofactor FAD and protonated nitrogen (Figure 1A) and therefore can only attack mono- or di-methylated lysines. The reaction is not matched with tri-methylated $\mathrm{H} 3-\mathrm{K} 4$ or, with any tri-methylated lysine substrate. The enzyme is specific for the methylated $\mathrm{H} 3-\mathrm{K} 4$, only in lysine residue. The enzyme, called as lysine-specific demethylase 1 (LSD1), has extensive sequence homology to metabolic FAD-dependent amine oxidases but contains a nuclear localization signal (NLS) and a SWIRM domain that can be found in chromatin-associated proteins. LSD1 with HDACs, is a component of Co-REST and other co-repressor complexes, some of which silence neuronal genes in non-neuron cells $(7,8)$. Knocking down LSD1 in HeLa cells result in increased H3-K4 di-methylation at endogenous target promoters of several neuron-specific genes concomitant with their transcriptional up-regulation (6).

The discovery of H3K4 demethylation by the amine oxidase family member LSD1 has significantly changed the concept of this field (5). This enzyme removes with remarkable specificity one or two methyl groups from $\mathrm{H} 3 \mathrm{~K} 4$ (H3K4me1/2) but cannot remove trimethylated H3K4 (H3K4me3). LSD1 was also demonstated to demethylate H3K9 (H3K9me1/2) upon interaction with the androgen receptor (9). It was proposed that another family of proteins containing Jumonji C $(\mathrm{JmjC})$ domains demethylates histone lysine residues (10), and an activity called JHDM1A that specifically catalyzes demethylation of H3K36 (H3K36me1/2) has been purified (11). The same group has purified a homologous $\mathrm{JmjC}$ protein that demethylates $\mathrm{H} 3 \mathrm{~K} 9 \mathrm{me} 2$ resulting in unmodified $\mathrm{H} 3 \mathrm{~K} 9$ (12). Moreover, various JMJD2 proteins were found to antagonize $\mathrm{H} 3 \mathrm{~K} 9 \mathrm{me} 3$ and $\mathrm{H} 3 \mathrm{~K} 36 \mathrm{me} 3$ biochemically and in vivo, resulting in $\mathrm{H} 3 \mathrm{~K} 9 \mathrm{me} 1 / 2$ and $\mathrm{H} 3 \mathrm{~K} 36 \mathrm{me} 1 / 2$, respectively (13). The mammalian Jmj protein family is large. The identification of histone lysine demethylases raises the possibility that all three degrees of methylation at these sites could be reversible. Histone 
demethylases should be particularly active during dynamic transitions in transcriptional regulation, such as at early stages of lineage commitment, thereby facilitating developmental plasticity of stem cellsn $(2,6)$. There are also mitotically stable repressive histone lysine modifications, such as $\mathrm{H} 3-\mathrm{K} 9$ and $\mathrm{H} 4-\mathrm{K} 20$ tri-methylation at pericentric heterochromatin and persistent H3-K27 tri-methylation at the inactive X chromosome (Xi) (14). Very early during $\mathrm{X}$ inactivation, $\mathrm{H} 3-\mathrm{K} 4$ tri-methyl is converted to di-methyl and then mono-methyl in a process that would be incompatible with histone cleavage or exchange. A specific histone lysine dioxygenase or hydroxylase can selectively remove H3-K4 tri-methylation. Similarly, there is very rapid DNA demethylation of 5-me $\mathrm{CpG}$ sites of the paternal genome immediately after fertilization $(15,16)$. It has been proposed the involvement of activationinduced deaminases (Aid) in the conversion of 5-me CpG to thymine (17).

The discovery of histone lysine demethylases has been demonstrated to impact the epigenetic alterations of histone lysine methylation (6). Demethylation of histone lysine residues does not change the fact that some methylation marks seem to be very stable and exhibit low turnover. The expression and/or activity of histone lysine demethylases must be tightly regulated in differentiated cells (6). Secondly, there is accumulating evidence that DNA methylation is reversible yet its epigenetic potential is not in dispute. DNA methylation is dependent on histone lysine methylation in various cases (18). Therefore, histone methylation marks may influence epigenetic status indirectly by regulating DNA methylation. Histone lysine demethylases also highly dynamic or are they stably bound to chromatin to preserve a demethylated state (6). There is significantly evident that one methyl mark by itself might have only a limited cellular entity. H3K9me3, for example, originally considered a hallmark of constitutive heterochromatin, was recently reported to be present at actively transcribed genes. Therefore, although H3K9me3 by itself might not correlate directly with transcriptional state, in combination with other histone marks, it might still donate to the final results. For histone lysine methylation, there are three methylation states including mono-, di-, and tri-methylation. Although amine oxidation and subsequent demethylation by LSD1 reflect a specific and genuine reversion to an unmodified histone lysine residue, it is only compatible with mono- and di-methylation (Figure 1A). Since di-methylation is converted to the ground state, LSD1 appears to be an enzyme that cannot remove tri-methyl groups from modified lysine positions (6). For this reaction, probably more potent enzymatic mechanisms are required. Oxidative demethylation or hydroxylation by radical reaction involving $\mathrm{Fe}(\mathrm{II})$ - and a-ketoglutaratedependent dioxygeneases $(6,10,19)$ could represent these missing enzymes. They would have the potential to disrupt histone lysine tri-methylation by direct oxidation of the methylcarbon, resulting in an unmodified lysine position and formaldehyde (Figure 1B). Until a decade ago, histone methylation was believed to be a stable modification that was only erased upon histone exchange or during DNA replication. However, this notion changed following the demonstration that lysine-specific demethylase 1 (LSD1) catalyses the demethylation of H3K4me1 and H3K4me2 (20). Subsequent studies led to the identification of a family of LSD enzymes containing the catalytic Jumonji C (JMJC) domain (20). Demethylating enzymes have now been characterized for most of the well-studied methylated lysines (20). Demethylation could, in certain circumstances, impose memory on gene transcription, and this could be a potential example of heritable epigenetic control 
where open chromatin or closed chromatin regulated by these histone lysine demethylases possible controls cellular signaling molecules such as tumor suppression, growth potential and apoptosis (Figure 1C).

Cancer is one of most complicated disease characterized by an abnormal and uncontrolled growth of cells that causes the formation of cellular masses and production of localized tumors. The different types of cancer affect about 13 million people worldwide and causing death of 8 million people annually (21). Cell growth and proliferation are controlled through post translational modifications particularly by demethylations that are tightly regulated by the enzymes demethylases These modification marks primarily localized at histone tails to regulate transcriptional machinery in cancers $(22,23)$. This review focusses on our current understanding of functional and therapeutic potentials of histone demethylases in colon cancer.

\section{Histone Demethylases and Colon Cancer}

Colon cancer is the third most common malignancy worldwide (24) and the second leading cause of cancer deaths in the United States (24). Drug resistance following recurrence and metastasis are the leading cause of death among colon cancer patients. Epithelialmesenchymal transition (EMT) is now considered to be the one of the initial and necessary steps in the metastatic cascade. Epithelial cells acquire fibroblast like characteristics following loss of cell polarity, reduced intercellular adhesion, increased motility and invasive capacity during EMT $(25,26)$. Transcription factors, such as snail, slug, zeb1, zeb2 and twist, can stimulate EMT by suppressing E-cadherin expression (25, 27-29) and consequently contribute to cancer metastasis.

Lysine-specific demethylase 1 (LSD1), the first discovered histone demethylase, is required for Snail/Slug-mediated transcriptional repression during EMT, in the absence of LSD1, Snail and Slug fail to repress E-cadherin transcription (25, 30-32). The Snail/Gfi-1 (SNAG) domain of Snail/Slug accumulates a histone H3-like structure and interacts with the LSD1CoREST complex, and brings this complex to its targeted gene promoters through the binding of the E-box through the zinc-finger motifs $(30,32)$. The LSD1/CoREST complex functions as a reversible nanoscale binding clamp, recruits and anchors a variety of substrate peptides with high sequence similarity to the H3-histone tail $(25,31,33,34)$. As a lysinespecific demethylase belonging to the flavin dependent amine oxidase family, LSD1 specifically catalyzed the demethylation of mono- and di-methylated histone $\mathrm{H} 3$ lysine 4 (H3K4) and H3 lysine 9 (H3K9) through a redox process (Figure 1A). Overexpression of LSD1 promotes proliferation, migration and invasion of various cancer cells $(34,35)$ and knocking down of LSD1 with small-interfering RNAs (siRNAs) resulted in suppression of proliferation and metastasis of various cancer cells $(25,36,37)$. Previous studies $(25,38)$ have shown that LSD1 had significantly higher expression, in contrast to the significantly lower expression of E-cadherin 1, in colon cancer at high tumor-node metastasis (TNM) stages (25) and with distant metastasis. Positive expression of LSD1 and negative expression of E-cadherin possibly suggest a worse prognosis of colon cancer. LSD1 may stimulate metastasis of colon cancer by decreasing the level of dimethylated histone H3 lysine4 $(\mathrm{H} 3 \mathrm{~K} 4 \mathrm{~m} 2)$ at the E-cadherin promoter and repressing E-cadherin transcription, which 
requires confirmation by further in vitro experiments. LSD1 was expressed significantly higher in colon cancer with higher TNM stages and distant metastasis. Inhibition of LSD1 impairs proliferation and invasiveness, and induces apoptosis of colon cancer cells in vitro (38). LSD1 down regulates the E-cadherin expression, and contributes to metastasis of colon cancer.

As a member of the monoamine oxidase (MAO) family, LSD1 catalyzes the specific demethylation of both mono- and di-methylated lysine 4 (K4) or lysine 9 (K9) of histone H3 (H3K4me1/2 or $\mathrm{H} 3 \mathrm{~K} 9 \mathrm{me} 1 / 2$ ) via a process that requires flavin adenine dinucleotide (FAD) as an essential redox cofactor (39-41). H3K4 methylation correlates with transcriptional activation, while H3K9 methylation with repression $(39,42)$. It indicated LSD1 plays an important role in transcriptional regulation $(39,40,43)$. It can selectively initiate or repress the transcription of target genes via demethylation of $\mathrm{H} 3 \mathrm{~K} 4$ or $\mathrm{H} 3 \mathrm{~K} 9$ by interacting with a variety of molecular partners. LSD1 participates in transcriptional repression as part of various protein complexes that contain several transcriptional co-repressors, promoter, including the REST, CoREST, RCOR2, BHC80, HDAC1/2, CtBP, BRAF35, NuRD etc. (44-47), and attributes the demethylation of H3K4me1/2. In contrast, when LSD1 interacts with androgen receptor (AR) or estrogen receptor (ER), it mediates the demethylation of $\mathrm{H} 3 \mathrm{~K} 9 \mathrm{me} 1 / 2$ to promote transcription (39-41). In addition to histone substrates, LSD1 has also been shown to demethylate lysine residues at several non-histone substrates, such as p53 (49), Dnmt1 (48), E2F1 (50), and MYPT1 (51). The ability to regulate such a wide range of substrates has linked LSD1 to abroad spectrum of biological processes, including cell proliferation $(39,52)$, chromosome segregation (53), hematopoiesis (54), spermatogenesis (55), adipogenesis (56), regulation of stem cell pluripotency (57), and embryonic development (58). The dysregulation of LSD1 activity has an important role in human tumorigenesis $(39,51)$, and studies have already been performed on breast cancer (59), prostate cancer (60), leukemia (61), lung cancer (62), bladder cancer (63), neuroblastoma (64), and colorectal cancer $(39,65)$. However, the role of LSD1 in colorectal cancer has not been clearly elucidated.

Dickkopf-1 (DKK1), a secreted protein, is known to be a negative regulator of the Wnt/Bcatenin signaling pathway (39). This pathway plays an important role in development and in regulating adult stem cell systems. A variety of cellular processes are mediated via Wnt/ $\beta$ catenin signaling, such as proliferation, differentiation, survival, apoptosis, and cell motility (66). Dysregulation of the pathway leads to tumorigenesis in several types of human cancers, including colorectal cancer $(39,66-70)$

Both LSD1 and DKK1 are associated with tumorigenesis. It has been reported that LSD1 contributes to colorectal tumorigenesis by downregulating DKK1 (39). DKK1 plays a key role here to link LSD1 to Wnt/b-catenin pathway and then to colorectal tumorigenesis (71). In addition to its ability to repress the transcription of target genes via demethylation of H3K4 by interacting with a variety of molecular partners (39), LSD1 can also repress transcription of target genes via DNA CpG dinucleotide methylation by demethylating and stabilizing Dnmt1 (39). This suggests that there might be two possible mechanisms of downregulation of DKK1 by LSD1. Wang et al reported that LSD1 demethylated and stabilized Dnmt1 in embryonic stem cells $(39,46)$, while Jin et al $(71)$ reported that LSD1 could not 
perform the similar function in HCT 116 (39). In conclusion, based on those reports it is plausible that LSD1 contributes to colorectal tumorigenesis via activation of the Wnt/3catenin signaling pathway by down-regulating the pathway antagonist DKK1 (39). Specifically, LSD1 down-regulates DKK1, which allows free b-catenin to avoid phosphorylation and degradation. Free b-catenin then accumulates and translocates to the nucleus, where it up-regulates the transcription of downstream target genes, including the oncogene c-Myc; the overexpression of c-Myc then causes the cells to transition to a malignant phenotype. This finding links LSD1 and DKK1 and elucidates the impact of LSD1 on the Wnt/ $\beta$-catenin signaling pathway activation and the pathway target genes to reveal the role of LSD1 in colorectal tumorigenesis (39).

With respect to non-histone JmjC substrates, mouse KDM6B interacts with p53 during neural stem cell differentiation and stabilizes $\mathrm{p} 53$ by demethylation, allowing its accumulation in the nucleus (72). The K218 and K221 residues of the p65 subunit of the nuclear factor $\kappa \mathrm{B}(\mathrm{NF}-\kappa \mathrm{B})$ may also be targets of KDM2A, which in this way negatively regulates NF- $\kappa \mathrm{B}$ activity and transcription.26. "pan-KDM" inhibitors can be obtained by coupling the chemical features of tranylcypromine, a known LSD1 inhibitor, with the 2,2'bipyridine or 5-carboxy-8HQ scaffolds, two $2 \mathrm{OG}$ competitive moieties developed for JmjC inhibition. Such compounds are able to inhibit LSD1 as well as JmjC enzymes while having little or no effect against other tested 2OG enzymes lacking KDM activity (72).

It is also interesting that the tranylcypromine moieties act as covalently binding inhibitors, whereas the JmjC inhibitor scaffolds bind reversibly (73). The application of such LSD/ JmjC hybrid inhibitors to cells enables simultaneous increases in levels of $\mathrm{H} 3 \mathrm{~K} 4 \mathrm{me} 2 / 3$ and $\mathrm{H} 3 \mathrm{~K} 9 \mathrm{me} 2 / 3$ as well as high growth arrest and apoptosis in HCT116 colon cancer cells, whereas the related family-specific single-target inhibitors were inactive. When tested in MePR noncancer cells to assess their differential toxicity, those inhibitors showed very low or no ability to increase the pre-G1 accumulation. It should be noted that since a single KDM may target multiple substrates, different biological effects depending on the context could manifest (73).

JHDM2A/JMJD1A/KDM3A is lysine (k)-specific demethylase 3A that specifically demethylates Lys-9 of histone $\mathrm{H} 3$, thereby playing an important role in histone code. It demethylates preferably mono- and dimethylated residue while it has weak or no activity on trimethylated H3 on Lys-9. JHDM2A has been shown to be novel prostatic marker in metastatic colorectal cancer cells that could be a promising therapeutic target for colon cancer (74).

In another study, KDM6b/JMJD3 is induced by vitamin $\mathrm{D}$ and modulates its effect in colon cancer cells (75). JMJD3/KDM6B, another member of Jumanji family, specifically demethylates bi- and tri-methylated Lys 27 residue of histone H3 (74). JMJD3 expression is induced by vitamin D metabolite 1a,25-dihydrooxyvitamin D3 (1,25(OH2D3) and that JMJD3 modulates gene regulatory action of this hormone. This compound activates JMJD3 gene promoter and increases the level of JMJD RNA in colon cancer cells (75). JMJD3 knockdown up-regulated the epithelial-to-mesenchymal transition inducers SNAIL1 and ZEB1 and the mesenchymal markers fibronectin and LEF1, while it down-regulated the 
epithelial proteins E-cadherin, Claudin-1 and Claudin-7. JMJD3 knockdown abolished the nuclear export of $\beta$-catenin and the inhibition of b-catenin transcriptional activity caused by $1,25(\mathrm{OH}) 2 \mathrm{D} 3$ and increases the expression of EMT inducers and mesenchymal markers.

(75) The expression of JMJD3 correlated directly with that of vitamin D receptor (VDR) and inversely with that of SNAIL1 in colon tumors. These results indicated that JMJD3 is a VDR co-target that partially mediates the effects of $1,25(\mathrm{OH}) 2 \mathrm{D} 3$ on human colon cancer. This study indicated that epigenetic regulator JMJD3 as a new $1,25(\mathrm{OH}) 2 \mathrm{D} 3$ target gene that in turn integrates with the gene regulatory actions of this vitamin D.

Few inhibitors targeting LSD1 and other FAD-dependent polyamine oxidases are available (76). The design of those inhibitors has been made on the basis on mechanism action of the enzymes. There are significant developments for identifying new potent inhibitors for LSD1 that inhibit LSD1 activity and also alter the growth of cancer cells (77). It has been demonstrated through in vitro and in vivo studies that nanomolar concentration phenocopied, a tranylcypromine analog and an inhibitor of LSD1 showed a pro-apoptotic activity in different cancer cells including colon cancer cells (77). Inhibition of LSD1 can increase the sensitivity for treatment with all-trans-retinoic acid (ATRA) in cancer (78). All these information suggested that LSD1 is a key therapeutic target for colon cancer.

In addition, iron and a-kg-dependent JmjC families' histone demethylases are also important target for identification of small inhibitors to understand the basis for the mechanism of the activity of these enzymes. Most well-known inhibitor targeting a-kg is Noxalylglycine $(20,21)$. These types of a-kg inhibitors usually compete with 2-oxoglutarate and Fe (II) binding to the catalytic domains of Jumanji-containing domain of histone demethylases.

\section{Conclusions}

The catalytic domain of these enzymes is well characterized with both full length protein structure of LSD family and some of the members of JmjC domain containing families. These domains have offered good understanding on mechanisms of enzyme activity and assisted in drug discovery. For better understanding on the biological role of KDMs, it will be plausible to use genetic models and study the effects of KDMs on cellular function, transcription and localization of histone marks (Figure 1C). Deletion of multiple families of KDMs could be important requirement to characterize the dynamics of KDM target genes in cancer. The generation of knockdown cells and knock-out animals should also provide better understanding in functional roles of KDMs in cancer progression and metastasis. Various $\mathrm{KDMs}$ from JmjC families are in preclinical studies in different types of cancer. In summary, this article emphasizes on understanding the functional and biological role of histone demethylases as epigenetic regulators in colon cancer.

\section{Acknowledgements}

This work was in part supported by NIH CA 151727 and by University of Kansas Cancer Center CCS1P30CA168524 Pilot Project Award to AD and by NIH Grants CA182872, CA19029, CA 109269, CA 135559 to SA.

Joaquina Baranda has received funding from Novartis to support her research as an investigator. 


\section{References}

1. Kubicek S, Jenuwein T. A crack of histone lysine demethylation. Cell. 2004; 119:903-906. [PubMed: 15620348]

2. Jenuwein T, Allis CD. Translating the histone code. Science. 2001; 293:1074-1080. [PubMed: 11498575]

3. Ahmad K, Henikoff S. Epigenetic consequences of nucleosome dynamics. Cell. 2002; 111:281-284. [PubMed: 12419239]

4. Bannister AJ, Schneider R, Kouzarides T. Histone methylation: dynamic or static. Cell. 2002; 109:801-806. [PubMed: 12110177]

5. Shi Y, Lan F, Matson C, et al. Histone demethylation mediated by the nuclear amine oxidase homolog LSD1. Cell. 2004; 119:941-953. [PubMed: 15620353]

6. Trojer P, Reinberg D. Histone lysine demethylases and their impact on epgentics. Cell. 2006; 125:213-217. [PubMed: 16630806]

7. Lunyak VV, Burgess R, Perfontaine GG, et al. Corepressor-dependent silencing of chrosomal regions encoding neural genes. Science. 2002; 298:1747-1752. [PubMed: 12399542]

8. Shi Y, Evans JE, Rock KL. Molecular identification of a danger signal that alerts the immune system to dying cells. Nature. 2003; 425:516-521. [PubMed: 14520412]

9. Metzer E, Wissman M, et al. LSD1 demethylates repressive histone marks to promote androgen transcription. Nature. 2002; 437:436-439.

10. Trewick, SSc; McLauhlin, PJ.; Allshire, RC. Methylation: lost in hydroxylation. EMBO Repots. 2005; 6:315-320.

11. Tsukada YI, Fang J, Erdjument-Bromage H, Warren ME, Borchers CH, Tempst P, Zhang Y. Nature. 2005; 439:811-816. [PubMed: 16362057]

12. Yamane K, Tateishi K, Klose RJ, Fang J, Fabrizio LA, Erdjument-Bromage H, TaylorPapadimitriou J, Tempst P, Zhang Y. PLU-1 is an H3K4 demethylase involved in transcriptional repression and breast cancer cell proliferation. Mol. Cell. 2007; 25:801-812. [PubMed: 17363312]

13. Whetstine JR, Nottke A, Lan F, Huarte M, Smolikov S, Chen Z, Spooner E, Li E, Zhang G, Colaiacovo M, Shi Y. Reversal of histone lysine trimethylation by the JMJD2 family of histone demethylases. Cell. 2006; 125:467-481. [PubMed: 16603238]

14. Wang Y, Wysocka J, Sayegh J, Lee YH, Perlin JR, Leonelli L, Sonbuchner LS, McDonald CH, Cook RG, Dou Y, et al. Human PAD4 regulates histone arginine methylation levels via demethylimination. Science. 2004; 306:279-283. [PubMed: 15345777]

15. O’Neill LP, Randall TE, Lavender J, Spotswood HT, Lee JT, Turner BM. X-linked genes in female embryonic stem cells carry an epigenetic mark prior to the onset of $\mathrm{X}$ inactivation. Hum. Mol. Genet. 2003; 12:1783-1790. [PubMed: 12874099]

16. Mayer W, Niveleau A, Walter J, Fundele R, Haaf T. Demethylation of the zygotic paternal genome. Nature. 2000; 403:501-502. [PubMed: 10676950]

17. Morgan HD, Dean W, Coker HA, Reik W. Petersen-Mahrt SK Activation-induced cytidine deaminase deaminates 5-methylcytosine in DNA and is expressed in pluripotent tissues: implications for epigenetic reprogramming. 2004; 279:52353-52360.

18. Tamaru H, Selker EU. A histone H3 methyltransferase controls DNA methylation in Neurospora crassa. Nature. 2001; 414:277-283. [PubMed: 11713521]

19. Falnes PØ1, Johansen RF, Seeberg E. AlkB-mediated oxidative demethylation reverses DNA damage in Escherichia coli. Nature. 2002; 419:178-182. [PubMed: 12226668]

20. Hojfeldt JW, Agger K, Helin K. Histone lysine demethylases as targets for anticancer therapy. Nat Rev. 2013; 12:917-930. In this review, authors highlighted key biological findings demonstrating the roles of members of the histone lysine demethylase class of enzymes in the development of cancers, discussed the potential and challenges of therapeutically targeting those enzymes, and highlighted emerging small-molecule inhibitors for these enzymes.

21. Lizcano F, Garcia J. Epigenetic control and cancer: The potential of histone demethylases as therapeutic targets. Pharmaceuticals. 2012; 5:963-990. [PubMed: 24280700] This review article offered the latest development regarding members of the recently described family of proteins that 
exhibited histone demethylase activity. Histone demethylases, genetic regulators, demonstrated a fundamental role in both the activation and repression of genes and whose expression increased in many types of cancer. Some important aspects of their association with the development of cancer and their relevance as potential targets for the development of new therapeutic strategies at the epigenetic level were discussed in this article.

22. Alebert M, Helin K. Histone methyltransferases in cancer. Semin. Cell Dev. Biol. 2010; 21:209_ 220. [PubMed: 19892027]

23. Pedersen TK, Helin K. Histone demethylases in development and disease. Trends Cell Biol. 2010; 20:662-671. [PubMed: 20863703]

24. Siegel R, Ma J, Zou Z, Jemal A. Cancer Statistics 2014. CA Cancer J Clin. 2014; 64:9-29. [PubMed: 24399786]

25. Ding J, Zhang Z-M, Xia Y, Liao G-Q, et al. LSD1-mediated epigenetic modification contributes to proliferation and metastatis of colon cancer. BR. J Cancer. 2013; 109:994-1003. [PubMed: 23900215] LSD1 was expressed significantly higher in colon cancer with higher TNM stages and distant metastasis. Inhibition of LSD1 impairs proliferation and invasiveness, and induces apoptosis of colon cancer cells in vitro. By removing dimethylation of lysine 4 on histone $\mathrm{H} 3$ (H3K4m2) at the CDH-1 promoter, LSD1 downregulates the CDH-1 expression, and contributes to metastasis of colon cancer.

26. Boyer B, Valles AM, Edme N. Induction and regulation ofepithelial-mesenchymal transitions. Biochem Pharmacol. 2000; 60:1091-1099. [PubMed: 11007946]

27. Kang Y, Massagué J. Epithelial-mesenchymal transitions: twist indevelopment and metastasis. Cell. 2004; 118:277-279. [PubMed: 15294153]

28. Waldmann J, Feldmann G, Slater EP, Langer P, Buchholz M, Ramaswamy A, Saeger W, Rothmund M, Fendrich V. Expression of the zinc-finger transcription factor Snail in adrenocortical carcinoma is associated with decreased survival. Br J Cancer. 2008; 99:1900-1907. (2008). [PubMed: 19018264]

29. Shah PP, Kakar SS. Pituitary tumor transforming gene induces epithelial to mesenchymal transition by regulation of Twist, Snail, Slug, and E-cadherin. Cancer Lett. 2011; 311:66-76. [PubMed: 21839581]

30. Lin Y, Wu Y, Li J, Dong C, Ye X, Chi YI, Evers BM, Zhou BP. The SNAG domain of Snail1 functions as a molecular hook for recruiting lysine-specific demethylase 1. EMBO J. 2010; 29:1803-1816. [PubMed: 20389281]

31. Baron R, Binda C, Tortorici M, McCammon JA, Mattevi A. Molecular mimicry and ligand recognition in binding and catalysis by the histone demethylase LSD1-CoREST complex. Structure. 2011; 19:212-220. [PubMed: 21300290]

32. Ferrari-Amorotti G, Fragliasso V, Esteki R, Prudente Z, Soliera AR, Cattelani S, Manzotti G, Grisendi G, Dominici M, Pieraccioli M, Raschellà G, Claudia C, Colombo MP, Calabretta B. Inhibiting interactions of lysine demethylase LSD1 with Snail/Slug blocks cancer cell invasion. Cancer Res. 2013; 73:235-245. [PubMed: 23054398]

33. Huang PH, Chen CH, Chou CC, Sargeant AM, Kulp SK, Teng CM, Byrd JC, Chen CS. Histone deacetylase inhibitors stimulate histone $\mathrm{H} 3$ lysine 4 methylation in part via transcriptional repression of histone H3 lysine 4 demethylases. Mol Pharmacol. 2011; 79:197-206. [PubMed: 20959362]

34. Cho HS, Suzuki T, Dohmae N, Hayami S, Unoki M, Yoshimatsu M, Toyokawa G, Takawa M, Chen T, Kurash JK, Field HI, Ponder BA, Nakamura Y, Hamamoto R. Demethylation of RB regulator MYPT1 by histone demethylase LSD1 promotes cell cycle progression in cancer cells. Cancer Res. 2011; 71:655-660. [PubMed: 21115810]

35. Lv T, Yuan D, Miao X, Lv Y, Zhan P, Shen X, Song Y. Over-expression of LSD1 promotes proliferation, migration and invasion in non-small cell lung cancer. PLoS One. 2012; 7:e35065. [PubMed: 22493729]

36. Hayami S, Kelly JD, Cho HS, Yoshimatsu M, Unoki M, Tsunoda T, Field HI, Neal DE, Yamaue H, Ponder BA, Nakamura Y, Hamamoto R. Overexpression of LSD1 contributes to human carcinogenesis through chromatin regulation in various cancers. Int J Cancer. 2011; 128:574-586. [PubMed: 20333681] 
37. Pollock JA, Larrea MD, Jasper JS, McDonnell DP, McCafferty DG. Lysine- specific histone demethylase 1 inhibitors control breast cancer proliferation in ERa-dependent and -independent manners. ACS Chem Biol. 2012; 7:1221-1231. [PubMed: 22533360]

38. Ding J, Liao G, Zhang Z, Wen J, Zeng L, Liu S, Zhang Y. Positive expression of LSD1 and negative expression of E-cadherin correlates with metastasis and poor prognosis of colon cancer. Dig Dis Sci. 2013; 58:1581-1589. [PubMed: 23314859]

39. Huang Z, Li S, Song W, et al. Lysine specific demethylase 1 (LSD1/KDM1A) contributes to colorectal tumorigenesis via activation of the Wnt/b-catenin pathway by down-regulating Dickkopf-1 (DKK1). Plos One. 2013; 8:e70077. [PubMed: 23922913] In this article, it was demonstrated that LSD1 down-regulated the Wnt/b-catenin signaling pathway antagonist, DKK1, and that this down-regulation affected free b-catenin levels to avoid degradation and accumulated in the cytoplasm. The free b-catenin then translocated to the nucleus, activated the transcription of the signaling pathway target gene c-Myc, and finally led to the aberrant proliferation of cells and tumorigenesis.

40. Shi Y, Lan F, Matson C, Mulligan P, Whetstine JR, et al. Histone demethylation mediated by the nuclear amine oxidase homolog LSD1. Cell. 2004; 119:945-953.

41. Metzger E, Wissmann M, Yin N, Muller JM, Schneider R, et al. LSD1 demethylates repressive histone marks to promote androgen-receptor-dependent transcription. Nature. 2005; 437:436-439. [PubMed: 16079795]

42. Martin C, Zhang Y. The diverse functions of histone lysine methylation. Nat Rev Mol Cell Biol. 2005; 6:838-849. [PubMed: 16261189]

43. Chosed R, Dent SY. A two-way street: LSD1 regulates chromatin boundary formation in S. pombe and Drosophila. Mol Cell. 2007; 26:160-162. [PubMed: 17466618]

44. Shi YJ, Matson C, Lan F, Iwase S, Baba T, et al. Regulation of LSD1 histone demethylase activity by its associated factors. Mol Cell. 2005; 19:857-864. [PubMed: 16140033]

45. Lee MG, Wynder C, Cooch N, Shiekhattar R. An essential role for CoREST in nucleosomal histone 3 lysine 4 demethylation. Nature. 2005; 437:432-443. [PubMed: 16079794]

46. Wang Y, Zhang H, Chen Y, Sun Y, Yang F, et al. LSD1 is a subunit of the NuRD complex and targets the metastasis programs in breast cancer. Cell. 2009; 138:660-672. [PubMed: 19703393]

47. Yang P, Wang Y, Chen J, Li H, Kang L, et al. RCOR2 is a subunit of the LSD1 complex that regulates ESC property and substitutes for SOX2 in reprogramming somatic cells to pluripotency. Stem Cells. 2011; 29:791-801. [PubMed: 21433225]

48. Huang J, Sengupta R, Espejo AB, Lee MG, Dorsey JA, et al. p53 is regulated by the lysine demethylase LSD1. Nature. 2007; 449:105-108. [PubMed: 17805299]

49. Wang J, Hevi S, Kurash JK, Lei H, Gay F, et al. The lysine demethylase LSD1 (KDM1) is required for maintenance of global DNA methylation. Nat Genet. 2009; 41:125-129. [PubMed: 19098913]

50. Kontaki H, Talianidis I. Lysine methylation regulates E2F1-induced cell death. Mol Cell. 2010; 39:152-160. [PubMed: 20603083]

51. Cho HS, Suzuki T, Dohmae N, Hayami S, Unoki M, et al. Demethylation of RB regulator MYPT1 by histone demethylase LSD1 promotes cell cycle progression in cancer cells. Cancer Res. 2011; 71:655-660. [PubMed: 21115810]

52. Scoumanne A, Chen X. The lysine-specific demethylase 1 is required for cell proliferation in both p53-dependent and -independent manners. J Biol Chem. 2007; 282:15471-15475. [PubMed: 17409384]

53. Lv S, Bu W, Jiao H, Liu B, Zhu L, et al. LSD1 is required for chromosome segregation during mitosis. Eur J Cell Biol. 2010; 89:557-563. [PubMed: 20189264]

54. Li Y, Deng C, Hu X, Patel B, Fu X, et al. Dynamic interaction between TAL1 oncoprotein and LSD1 regulates TAL1 function in hematopoiesis and leukemogenesis. Oncogene. 2012; 31:50075018. [PubMed: 22310283]

55. Godmann M, Auger V, Ferraroni-Aguiar V, Di Sauro A, Sette C, et al. Dynamic regulation of histone H3 methylation at lysine 4 in mammalian spermatogenesis. Biol Reprod. 2007; 77:754764. [PubMed: 17634443]

56. Musri MM, Carmona MC, Hanzu FA, Kaliman P, Gomis R, et al. Histone demethylase LSD1 regulates adipogenesis. J Biol Chem. 2010; 285:30034-30041. [PubMed: 20656681] 
57. Zhou H, Li W, Zhu S, Joo JY, Do JT, et al. Conversion of mouse epiblast stem cells to an earlier pluripotency state by small molecules. J Biol Chem. 2010; 285:29676-29680. [PubMed: 20705612]

58. Foster CT, Dovey OM, Lezina L, Luo JL, Gant TW, et al. Lysine-specific demethylase 1 regulates the embryonic transcriptome and CoREST stability. Mol Cell Biol. 2010; 30:4851-4863. [PubMed: 20713442]

59. Lim S, Janzer A, Becker A, Zimmer A, Schule R, et al. Lysine-specific demethylase 1 (LSD1) is highly expressed in ER-negative breast cancers and a biomarker predicting aggressive biology. Carcinogenesis. 2010; 31:512-520. [PubMed: 20042638]

60. Wu CY, Hsieh CY, Huang KE, Chang C, Kang HY. Cryptotanshinone down-regulates androgen receptor signaling by modulating lysine-specific demethylase 1 function. Int J Cancer. 2012; 131:1423-1434. [PubMed: 22052438]

61. Schenk T, Chen WC, Gollner S, Howell L, Jin L, et al. Inhibition of the LSD1 (KDM1A) demethylase reactivates the all-trans-retinoic acid differentiation pathway in acute myeloid leukemia. Nat Med. 2012; 18:605-611. [PubMed: 22406747]

62. Lv T, Yuan D, Miao X, Lv Y, Zhan P, et al. Over-expression of LSD1 promotes proliferation, migration and invasion in non-small cell lung cancer. PLoS One. 2012; 7:e35065. [PubMed: 22493729]

63. Kauffman EC, Robinson BD, Downes MJ, Powell LG, Lee MM, et al. Role of androgen receptor and associated lysine-demethylase coregulators, LSD1 and JMJD2A, in localized and advanced human bladder cancer. Mol Carcinog. 2011; 50:931-944. [PubMed: 21400613]

64. Schulte JH, Lim S, Schramm A, Friedrichs N, Koster J, et al. Lysinespecific demethylase 1 is strongly expressed in poorly differentiated neuroblastoma: implications for therapy. Cancer Res. 2009; 69:2065-2071. [PubMed: 19223552]

65. Huang Y, Greene E, Murray Stewart T, Goodwin AC, Baylin SB, et al. Inhibition of lysinespecific demethylase 1 by polyamine analogues results in reexpression of aberrantly silenced genes. Proc Natl Acad Sci U S A. 2007; 104:8023-8028. [PubMed: 17463086]

66. Willert K, Jones KA. Wnt signaling: is the party in the nucleus? Genes Dev. 2006; 20:1394-1404. [PubMed: 16751178]

67. Ilyas M. Wnt signalling and the mechanistic basis of tumour development. J Pathol. 2005; 205:130-144. [PubMed: 15641015]

68. Clevers H. Wnt/beta-catenin signaling in development and disease. Cell. 2006; 127:469-480. [PubMed: 17081971]

69. Turashvili G, Bouchal J, Burkadze G, Kolar Z. Wnt signaling pathway in mammary gland development and carcinogenesis. Pathobiology. 2006; 73:213-223. [PubMed: 17314492]

70. Colnot S, Decaens T, Niwa-Kawakita M, Godard C, Hamard G, et al. Liver-targeted disruption of Apc in mice activates beta-catenin signaling and leads to hepatocellular carcinomas. Proc Natl Acad Sci U S A. 2004; 101:17216-17221. [PubMed: 15563600]

71. Jin L, Hanigan CL, Wu Y, Wang W, Park BH, et al. Loss of LSD1 (lysinespecific demethylase 1) suppresses growth and alters gene expression of human colon cancer cells in a p53- and DNMT1(DNA methyltransferase 1)-independent manner. Biochem J. 2013; 449:459-468. [PubMed: 23072722]

72. Klaus A, Birchmeier W. Wnt signalling and its impact on development and cancer. Nat Rev Cancer. 2008; 8:387-398. [PubMed: 18432252]

73. Rotli D, Tomassi S, Conte M, Benedette R, et al. Pan-histone demethylase inhibitors simultaneously targeting Jumanji $\mathrm{C}$ and lysine-specific demethylases display high anticancer activities. J. Med. Chem. 2014; 57:42-55. [PubMed: 24325601]

74. Uemura M, Yamamoto H, Takemasa I, Mimori K, Hemmi H, Mizushima T, Ikeda M, Sekimoto M, Matsuura N, Doki Y, Mori M. Jumonji domain containing 1A is a novel prognostic marker for colorectal cancer: in vivo identification from hypoxic tumor cells. Clin. Cancer Res. 2010; 16:4636-4646. [PubMed: 20823141] JMJD1A could be a sensitive biomarker for hypoxic tumor cells and a poor prognosis of CRC. Our data also suggest that JMJD1A may be a novel therapeutic target, especially against tumor cells in a hypoxic condition. 
75. Preira F, Barbachano A, Silva J, et al. KDM6B/JMJD3 histone demethylase is induc4ed by vitamin D and modulates its effects in colon cancer cells. Human Mo. Genetics. 2011; 20:4655-4665.

76. Lizcano F, Garcia J. Epigenetic control and cancer: The potential of histone demethylases as therapeutic targets. Pharmaceuticals. 2012; 5:963-990. [PubMed: 24280700]

77. Schenk T, Chen WC, Gollner S, Howell L, Jin L, Hebestreit K, Klein HU, Popescu AC, Burnett A, Mills K, et al. Inhibition of the LSD1 (KDM1A) demethylase reactivates the all-trans-retinoic acid differentiation pathway in acute myeloid leukemia. Nat. Med. 2012; 18:605-611. [PubMed: 22406747]

78. Hamada S, Suzuki T, Mino K, Koseki K, Oehme F, Flamme I, Ozasa H, Itoh Y, Ogasawara D, Komaarashi H, et al. Design, synthesis, enzyme-inhibitory activity, and effect on human cancer cells of a novel series of jumonji domain-containing protein 2 histone demethylase inhibitors. J. Med. Chem. 2010; 53:5629-5638. [PubMed: 20684604]

79. Rose NR, Woon EC, Kingham GL, King ON, Mecinovic J, Clifton IJ, Ng SS, Talib-Hardy J, Oppermann U, McDonough MA, et al. Selective inhibitors of the JMJD2 histone demethylases: Combined nondenaturing mass spectrometric screening and crystallographic approaches. J. Med. Chem. 2010; 53:1810-1818. [PubMed: 20088513] 
A

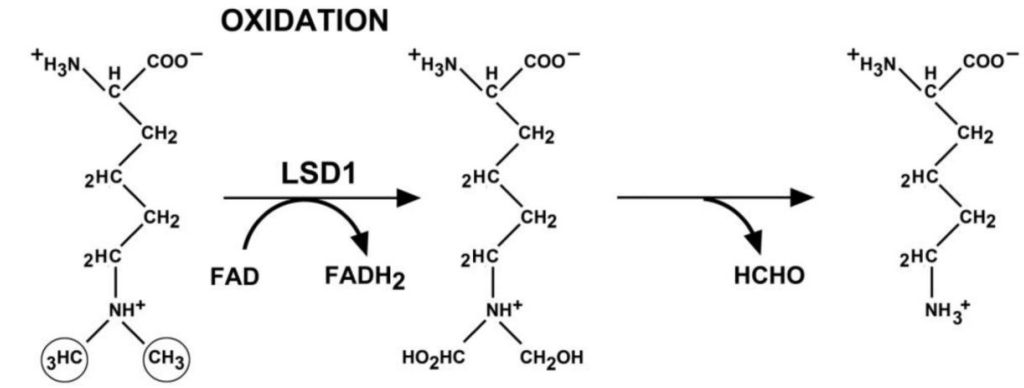

Di-methylated Lysine

Lysine

B

OXYGENATION
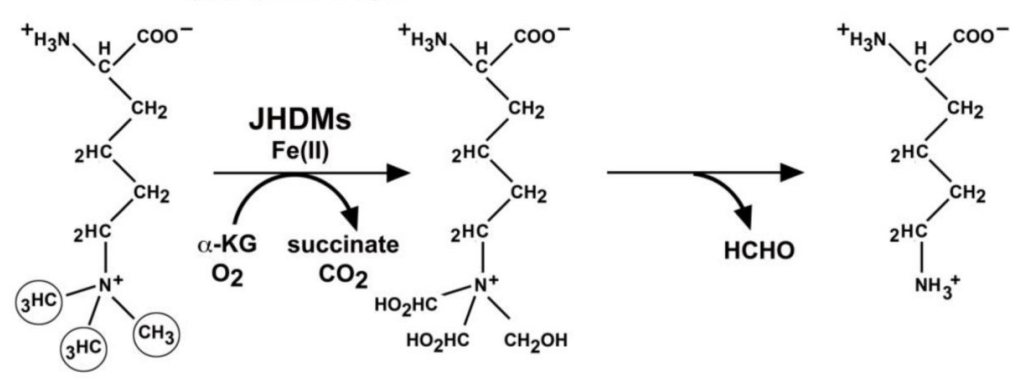

Tri-methylated Lysine

Lysine

C

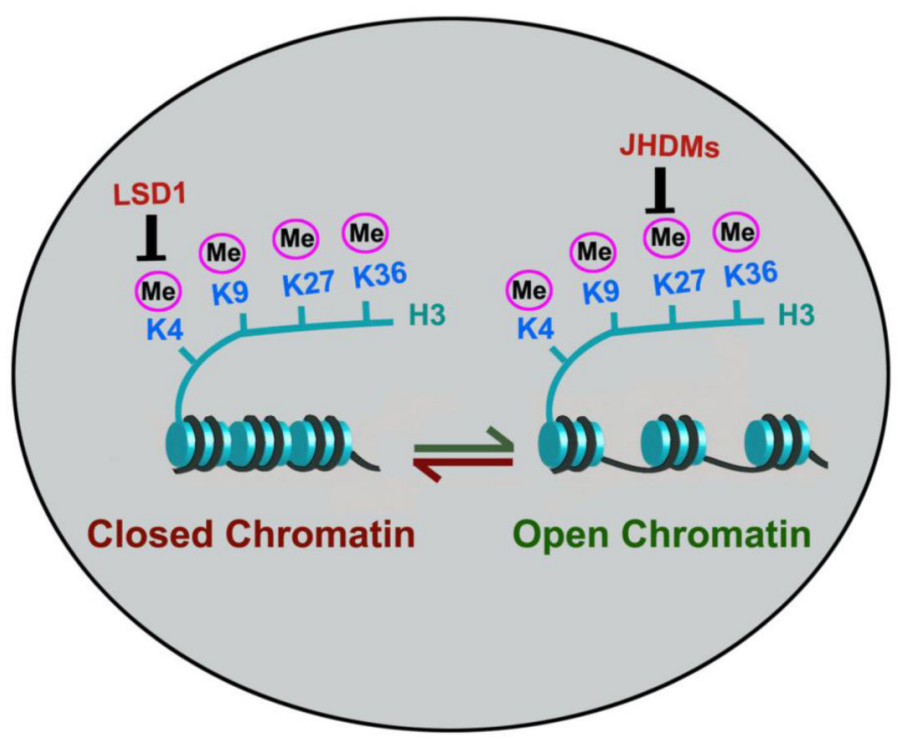

Figure 1.

A. Lysine specific demethylase (LSD) catalyzes demethylation of histone.

These enzymes are responsible for an FAD-dependent activity that implicate at least one atom of hydrogen on the amine group of lysine suggesting the activity of these enzymes on the mon- and dimethylated of lysine.

B. Jumanji domain demethylase protein (JHDM/JMJD) catalyzes demethylation of dimethylated histone. 
These enzymes are dependent on oxygenase activities which are capable of adding a hydroxyl group to methyl group in lysine residue in an a-ketoglutarate $(\mathrm{a}-\mathrm{kg})$ and $\mathrm{Fe}++$ dependent manner during the conversion of a-kg into succinate and $\mathrm{CO}_{2}$ followed by spontaneous release of formaldehyde.

C. Model of involvement of demetheylases in transcriptional regulation of metastatic and tumor suppressor genes

Closed chromatin or Hetrochromatin regulated by LSD1 is responsible for tumor suppressor gene silencing and metastatic aggressiveness wheres open chromatin or Euchromatin reexpresses of tumor suppression genes and actiavtion of apoptosis inducing factors for growth inhibition. 